\title{
O LEGADO DA ARQUITETURA DO SÉCULO XX: PROTEÇÃO ADMINISTRATIVA VERSUS SALVAGUARDA EFETIVA.
}

RICHARD KLEIN, ESCOLA NACIONAL SUPERIOR DE ARQUITETURA E PAISAGEM, LILLE, FRANÇA. Professor na École Nationale Supérieure d'Arquitetura et de Paysage (Escola Nacional Superior de Arquitetura e de Paisagem) de Lille (França). Diretor do Lacth.

DOI

http://dx.doi.org/10.11606/issn.1980-4466.v0iesp21p14-30 
O LEGADO DA ARQUITETURA DO SÉCULO XX: PROTEÇÃO ADMINISTRATIVA VERSUS SALVAGUARDA EFETIVA.

RICHARD KLEIN

\section{RESUMO}

$\mathrm{O}$ artigo aborda, num primeiro momento, os instrumentos franceses da proteção do patrimônio arquitetônico e urbano e a sua evolução e, em seguida, as questões levantadas pelo legado arquitetônico do século XX. Objeto de muitas desnaturações e destruições, o futuro deste legado questiona os valores tradicionais que normalmente justificam o reconhecimento patrimonial. Os conhecimentos materiais e culturais da arquitetura do século XX são apresentados como condições indispensáveis para a sua salvaguarda efetiva frente a uma proteção administrativa muitas vezes ineficiente.

\section{PALAVRAS-CHAVE}

Patrimônio arquitetônico. Arquitetura moderna. Planejamento territorial urbano. 


\title{
THE LEGACY OF THE 20TH CENTURY ARCHITECTURE: ADMINISTRATIVE PROTECTION VERSUS EFFECTIVE SAFEGUARD. \\ RICHARD KLEIN
}

\begin{abstract}
This article covers the French instruments for protecting the architectural and urban heritage, as well as its evolution. It will also cover the issues raised by the twentieth century architectural legacy. Subject to denaturing and destruction, the future of this legacy questions traditional values that usually serve as rationale for the recognition as a heritage site. The material and cultural knowledge about twentieth century architecture are presented as essential conditions to effectively safeguard it opposed to a usually ineffective administrative protection.
\end{abstract}

\section{KEYWORDS}

Architectural heritage. Modern architecture. Urban territory planning. 
Legado da Revolução Francesa e de uma visão centralizada do território nacional, o sistema administrativo francês de proteção do patrimônio nunca parou de evoluir e de se transformar desde o início. Para os edifícios, a proteção administrativa possui dois níveis: o tombamento e o registro a título de monumentos históricos. $\mathrm{O}$ tombamento a título de monumentos históricos baseia-se, inicialmente, no interesse público da conservação dos edifícios de acordo com pontos de vista históricos ou artísticos. A frase que inicia a lei de 31 de dezembro de 1913 é explícita: "os edifícios, cuja conservação apresentam, de um ponto de vista da história ou da arte, um interesse público, são tombados como monumentos históricos". O registro foi inicialmente pensado como a antessala do tombamento: "Os edifícios que, sem justificarem um pedido de tombamento imediato, apresentam um interesse de história ou de arte suficiente para que seja desejável a sua preservação, poderão, a qualquer momento, ser registrados num inventário adicional" como esclarece em 1927, o artigo II da Lei de 1913. O registro é considerado, na maioria das vezes, como um nível inferior de proteção administrativa, definido pela restrição frequentemente utilizada nos documentos oficiais que limita a proteção à "fachada e à cobertura", o que permite imaginar, somente por esta formulação, o tamanho das dificuldades geradas em matéria de gestão do patrimônio. A Lei de 1913 sobre os monumentos históricos adaptou-se gradualmente 
à ampliação da noção de patrimônio e as proteções administrativas integraram, dos edifícios representativos do interesse público, mais que a representação nacional que constituíra as primeiras escolhas, mas também, aos poucos, as arquiteturas tradicionalmente excluídas da cultura erudita, como as arquiteturas concebidas em períodos mais contemporâneos, as arquiteturas vernaculares ou industriais.

As consequências para a gestão urbana desta proteção a título de monumentos históricos são ligadas à implantação de um perímetro de proteção, um perímetro de 500 metros, no qual os alvarás de construção são submetidos a autorizações prévias dos serviços do estado.

Desde a criação do Ministério da Cultura, em 1959, as dimensões urbanas e paisagísticas do patrimônio completam, progressivamente, a base do dispositivo elaborado para os edifícios. Em 1962, são criados os setores salvaguardados. Os setores salvaguardados são pedaços de cidade que apresentam "um caráter histórico, estético ou de natureza a justificar a conservação, restauro e valorização". Esta medida visa essencialmente os centros antigos ${ }^{12}$.

A partir de 1964, o Inventário Geral torna-se um instrumento de conhecimento do patrimônio nacional. As campanhas de inventário realizadas com lógicas territoriais e cuja ambição era identificar todos os componentes, "da colherinha até a catedral", são completadas de forma progressiva por campanhas de inventários temáticos, voltadas para a arquitetura industrial, arquitetura balneária, arquitetura rural ou as arquiteturas do espetáculo, por exemplo. Em 1983, a proteção dos conjuntos urbanos atinge uma nova dimensão com a criação das Zones de Protection du Patrimoine Architectural et Urbain (Zonas de Proteção do Patrimônio Arquitetônico e Urbano), que viraram, em 1993, as Zones de Protection du Patrimoine Architectural Urbain et Paysager (Zonas de Proteção do Patrimônio Arquitetônico Urbano e Paisagístico, as ZPPAUP). Estes setores, em 2010, tornam-se as Áreas de Valorização da Arquitetura e do Patrimônio (AVAP). Destaca-se como a lógica das ZPPAUP representa um considerável avanço no envolvimento das dimensões urbanas e paisagísticas

1. Somente um setor salvaguardado na França diz respeito às arquiteturas dos séculos XIX e XX. Está localizado na cidade balneária de Mers les Bains.

2. O padre "Abbé Pierre", fundador da associação Emmaüs, é o autor do chamado radiofônico lançado no dia $1^{\circ}$ de fevereiro de 1954 , depois da morte de uma criança. 
da proteção do patrimônio. O princípio das ZPPAUP é de substituir o perímetro administrativo de 500 metros por um perímetro ponderado, fundamentado num estudo histórico e morfológico da área ao redor dos edifícios protegidos. No perímetro de 500 metros, a aprovação dos representantes do estado do alvará de construção é ligada à visibilidade da nova construção e do edifício tombado. Na ZPPAUP, os laudos da administração são fundamentados em um regulamento proveniente do estudo preliminar e concebido logicamente em acordo com o conjunto dos parceiros envolvidos.

A criação do selo "Patrimônio do século XX", no início de século XXI", simboliza ao mesmo tempo os esforços, mas também as dificuldades, da consideração da salvaguarda da arquitetura do século XX - apesar da existência de todos estes dispositivos administrativos de proteção. Este selo - "século XX” - não possui nenhuma incidência jurídica. Ele foi o meio concebido pelo Ministério da Cultura para designar edifícios cujo interesse é reconhecido, mas cuja proteção, a título de monumentos históricos, parece difícil ou ainda cercada de muitas dúvidas. Esta última "invenção" do Ministério da Cultura provoca efeitos variáveis de acordo com o caso e as regiões. Muitos edifícios ou conjuntos urbanos certificados não escaparam a desnaturações ou destruições. As boas intenções deste selo não compensaram a sua ausência de efeito jurídico. Nos melhores casos, os edifícios certificados entraram, de forma progressiva, na lista dos edifícios registrados a título de monumentos históricos. Mas, desde a sua instauração é, principalmente, a longa lista dos edifícios destruídos do século XX que faz as manchetes da crônica patrimonial.

Consideradas, há pouco,com desprezo e condescendência, as arquiteturas do século XX e, principalmente, aquelas edificadas depois da Segunda Guerra Mundial, estão sofrendo pela falta de reconhecimento. Condicionadas pela novidade dos programas, as formas destas arquiteturas são, porém, as formas de uma produção de componentes inventivos, inovações tecnológicas e novos materiais no contexto dinâmico de renovação das artes plásticas e das ciências humanas. Elas são, na França, as herdeiras de 40 anos de desprezo sistemático do qual podemos observar os fundamentos ideológicos nos debates do período entre as duas guerras. Desde a reconstrução nacional depois da Primeira Guerra 
Mundial, as vanguardas arquitetônicas francesas sofreram críticas virulentas que deixaram profundas marcas na cultura construtiva ou popular. Desde que a modernidade foi assimilada à Revolução Soviética ou ao racionalismo germânico, os inimigos de ontem, é difícil fazê-la passar como uma expressão nacional. A arquitetura do século XX deve enfrentar, ainda, outro fenômeno ligado à crise energética e ao domínio, na França, das soluções de isolamento feitas no exterior. Em 2015, a carta de intenções da Sociedade para a Proteção e Estética da França trata deste assunto, mostrando o ridículo projeto da embalagem térmica de uma modesta igreja de aldeia desfigurada.

\section{O LEGADO DO SÉCULO XX}

Existe um contraste impressionante - com algumas décadas de distância - entre a apreciação inicial das arquiteturas dos anos 1960 e o modo como são consideradas na nossa época contemporânea. Em 1972, no último Guia de Arquitetura Contemporânea na França lançado antes da crise do petróleo e da crise econômica de 1973, os comentários sobre o conjunto habitacional de Villeneuve-la-Garenne (Jean Dubuisson arquiteto, 1965) são muitos elogiosos e até um pouco líricos. Estamos sete anos depois da conclusão da construção:

Gênio inventivo de um plano de massas que soube alternar amplas ágoras indispensáveis à prática comunitária de uma democracia da troca e do diálogo; fluxos de verdura onde as donas de casa gostam de se encontrar para conversar, tranquilamente sentadas em seus barris de Bonux; parques infantis, tão úteis para o desenvolvimento intelectual e afetivo das crianças; trilhas para caminhar, onde os trabalhadores encontram ainda o tempo de passear. Arquitetura na escala humana que se libertou audaciosamente dos condicionamentos técnicos, sociais, políticos e financeiros para dar livre curso a suas pulsões, fantasias, delírios ${ }^{4}$ (AMOUROUX; CRETTOL; MONNET, 1972, p. 379).

O conjunto concebido pelo Jean Dubuisson em Villeneuve-la-Garenne tornou-se justamente o emblema, na França, de certo gênero de reestruturação

\footnotetext{
4. D. Amouroux, M. Crettol, J.P. Monnet, (cobertura de Jean Dewasne) Guide d'arquitetura contemporaine en France, Madrid, AA, Technic-union, 1972, p.379.
} 
das habitações coletivas dos anos 1960. Poderíamos comparar cada termo dos comentários de elogios escritos em 1972 pelos autores do guia com o comentário dos autores do projeto da sua reestruturação contemporânea que afirmam a necessidade de:

“(...) introduzir complexidade urbana, jardins, ruas, praças e passagens.

A remodelação: o nosso objetivo é trabalhar como um segundo estrato sobre uma base hiper-racionalista que percebemos como muito lisa, muito repetitiva e pobre. Agir em dois campos, o da percepção e o do uso:

A percepção:

- Sequenciar, delimitar, reencontrar medidas.

-Materializar, identificar: os embasamentos dos edifícios estão atualmente esmagados, é necessário engrossá-los para afirmar o seu status. É preciso redesenhar para dar mais visibilidade às entradas. As bow windows adoçam e ritmam estas longas lâminas. Como demos uma base aos edifícios, revelamos o topo com um coroamento.

A residencialização: além da modenatura; pedestal, corpo, céu, nós damos uma escala residencial a este conjunto. As grandes lâminas são subdivididas em entidades identificáveis dentro dos bairros.

As habitações: mesmo bem dispostas, as habitações existentes são hiperfuncionais. As suas tipologias são pouco variadas e sofrem o efeito do empilhamento" ${ }^{5}$ (CASTRO; DENISSOF, 2011).

O segundo comentário apoia-se claramente numa crítica implícita aos valores destacados pelo primeiro.

O gênio inventivo de um plano de massa torna-se uma base hiper-racionalista, as amplas ágoras, prática comunitária da democracia e da troca e do diálogo devem ser tratadas pela residencialização, uma escala residencial. As grandes lâminas são subdivididas em entidades identificáveis. Os fluxos de verdura, parques infantis, as trilhas para caminhada, em 1972 dão lugar a uma arquitetura muito lisa, muito repetitiva e pobre na qual se precisa introduzir complexidade urbana,

5. Estas linhas são extraídas do texto apresentando o projeto de reestruturação do conjunto da Caravelle no site dos arquitetos Roland Castro e Sophie Denissof. (http://www.castrodenissof.com, consultado em 12 de maio de 2011). 
jardins, ruas, praças e passagens, e precisa sequenciar e delimitar a escala humana inicial. (CASTRO; DENISSOF, 2011)

São valores supostos da cidade antiga que são a referência do olhar crítico num conjunto dos anos 1960. O plano de massa da reestruturação proposta e feito, portanto, à imagem e semelhança das reestruturações dos conjuntos habitacionais coletivos que, desde mais ou menos 30 anos, caracterizam estas operações na França e baseiam-se essencialmente sobre apreciações negativas do existente que resultam em destruições materiais.

Os conjuntos de habitações coletivas não são as únicas arquiteturas a endossar este contraste do julgamento entre a consideração inicial e a desvalorização contemporânea. O caso das casas de cultura, principal programa do Ministério da Cultura a partir de 1960, é significativo de como a celebração passada deixou lugar à negação contemporânea que se traduziu pelas transformações radicais dos mais belos exemplos arquitetônicos deste programa. Enquanto, em 1966, “(...) os moradores de Amiens estavam orgulhosos por possuir doravante a mais bela Casa de Cultura Francesa, e toda região da Picardie apaixona-se por esta realização, cuja fama já atraiu muitos ônibus de visitantes", em 1999, acham-na "rebarbativa" por fora”.

Estes comentários e este contraste estão mais ligados à ideologia do que à análise crítica ou análise do valor. Ideologia da cidade antiga e histórica que se opõe à cidade moderna. Ideologia mais política na hora da transformação da Casa de Cultura de Amiens que, após uma alteração de governo municipal passa de um equipamento emblemático de uma cidade dirigida por um prefeito comunista para um equipamento coberto por uma "faixa azul" para retomar os termos dos arquitetos que dirigiram as transformações. Rem Koolhaas, um arquiteto que não é conhecido como nostálgico nem defensor das causas patrimoniais, fazia comentários bastante edificantes sobre esta situação durante uma das

6. A Casa da Cultura de Amiens, comentada na revista L’arquitetura Française, n. 283-284, abr. 1966. p.79 7. A Casa da Cultura de Amiens, comentada em Amiens au fil du regard, Bayeux, edições Martelle, 1999. Os Arquitetos da Casa de Cultura de Amiens (1965) são Pierre Sonrel, Jean Duthilleul e Marcel Gogois. O edifício foi transformado em 1993 pelos arquitetos Gilles Duez, Roland Gaignart, e Igor Hilbert. 
últimas bienais de arquitetura em Veneza (2010) sobre a demolição do Palácio da República em Berlim: "Mau gosto ou ideologia? A intolerância da nossa geração é impressionante. Se os critérios que originaram a eliminação do Palácio da República de Berlim fossem aplicados à arquitetura antiga, por exemplo, à arquitetura romana, não sobraria nenhum vestígio histórico dela"9.

Nessa oportunidade, ele estabelecia um balanço bem triste da recente destruição de edifícios construídos nos anos 1960 e cuja lista incluía alguns exemplares destacados no seu tempo pela crítica e pela história contemporânea da arquitetura.

Estes textos e imagens devem, evidentemente, fazer-nos refletir sobre a forma como consideramos (ou desconsideramos) a herança das arquiteturas dos anos 1960. Manifestamente, não somos mais capazes de olhá-las como o faziam os fotógrafos da revista L'œil, em 1964, que ofereciam uma visão positiva e estetizante a fim de ilustrar propósitos que, às vezes, eram até críticos. Nem de apreciarmos as proezas técnicas louvadas pelas empresas que erigiram, naquele momento, as construções mais espetaculares. Nós e as instituições patrimoniais retemos facilmente só as arquiteturas que possuem um caráter excepcional, e que são mais conformes com o valor artístico que pode ser usado para justificar uma consideração positiva.

\subsection{Legado?}

$\mathrm{Na}$ obra Les années ZUP, architecture de la croissance $^{10}$, publicada em 2002, assinalamos com Gérard Monnier a condescendência e o desprezo dos comentários sobre as arquiteturas do período entre 1930 e 1980. Insistimos sobre a necessidade do estudo sistemático da arquitetura daqueles anos, que ainda precisamos conhecer precisamente. Para nós, tratava-se de enfrentar a sua "invisibilidade", destacando alguns exemplos.

8. Heinz Graffunder arquiteto (Karl-Ernst Swora, Wolf R. Eisentraut, Günter Kunert, Manfred Prasser et Heinz Aust collaborateurs).

9. Rem Koolhaas, bienal de Veneza, 2010.

10. Richard Klein \& Gérard Monnier (dir.) Les années ZUP, arquiteturas de la croissance 1960-73, Picard, Paris, 2002. 
Para uma série de arquiteturas que incluem os conjuntos habitacionais coletivos e os programas de equipamentos públicos com somente um pouco mais de 40 anos de idade, estamos enfrentando uma falta de evidências materiais e devemos nos contentar com fontes documentais. Estes edifícios desapareceram ou são irreconhecíveis. A arquitetura do pequeno comércio, por exemplo, sumiu, e as cidades perderam todos os sinais desta modernidade diária que invadia o espaço urbano. Outros programas foram submetidos a um nível intensivo de renovação formal ou funcional: a arquitetura comercial, a de lazer e do turismo, das infraestruturas de transporte, dos serviços administrativos, dos locais da produção industrial ou dos espaços do trabalho terciário.

O primeiro motel francês, perdido numa estação balneária e transformado, 10 anos apenas após a sua construção, tornou-se invisível. É totalmente desconhecido, e somente o fato de ter sido imortalizado pelo primeiro filme de Louis Malle (Ascenseur pour léchafaud, 1957), do qual constituía o cenário, pode ainda atrair a atenção para os seus belos vestígios materiais. Louis Malle, que queria dar uma aparência mais moderna do que a realidade do ambiente francês no final dos anos 1950, percebera toda a modernidade deste novo programa importado dos Estados Unidos ${ }^{11}$.

Outro fator de invisibilidade patrimonial está ligado às dúvidas que acometeram atores do período. Guy Lagneau, para a reestruturação do Museu do Havre, e André Wogenscky, para a reestruturação da Casa da Cultura de Grenoble, não foram os maiores defensores das suas obras. Já era bastante excepcional que os contratantes pedissem a opinião deles em qualidade de criador original do edifício. Jean Dubuisson, como outros, admitia ser oprimido por um sentimento de culpa e deixou desfigurar a residência do Parc à Croix (Norte), grande prêmio de urbanismo do seu tempo. Estes arquitetos, como outros, sofreram com o contexto de desprezo midiático, popular, algumas vezes caucionado pelo discurso erudito que, há 30 anos, critica fortemente, no mesmo amálgama, o concreto armado, os grandes conjuntos ou a austeridade das formas da arquitetura da segunda metade do século XX. Há mais de 40 anos, na França,

11. Neste assunto, Richard Klein, "Nouveaux programmes de l’arquitetura balnéaire, Le Touquet, du paradis des sports à la station des quatre saisons", Revue de l'Art, n.165, 2009-3 (setembro 2009). p. 49-55. 
não há nenhum programa de televisão, nenhum telejornal em que não se critica o concreto, os grandes conjuntos e globalmente, a arquitetura dos "30 gloriosos" (os anos do crescimento econômico). As recentes polêmicas sobre a comemoração do cinquentenário da morte de Le Corbusier mostraram como os atalhos históricos foram diretamente ao objetivo e deixaram entender que a arquitetura do grande número tem as suas raízes nas ideologias repressivas. Além disso, as transformações e manutenção cotidianas destas arquiteturas recentes são muitas vezes entregues, na França, ao realismo do mercado ${ }^{12}$. Consideradas de um ponto de vista utilitário, estas arquiteturas são tratadas sem muita atenção ao grado das adaptações às conformidades normativas ou da evolução dos usos.

\section{MODÉSTIA DA ARQUITETURA, INTELIGÊNCIA DO COMPONENTE}

Lionel Schein via no Instituto do Meio Ambiente (1968-1969, Robert Joly, arquiteto) um exemplo de arquitetura mecanicista composta a partir de um "arsenal arquitetônico" muito pouco usado na França ${ }^{13}$. Neste edifício desparecido há aproximadamente 15 anos, a administração propusera ao arquiteto a utilização de painéis de fachada concebidos por Jean Prouvé e a Compagnie Industrielle de Matériel de Transport. O programa dava grande importância à flexibilidade de uso, às possibilidades de transformação do arranjo interno e aos objetivos de custo e prazo da obra. Os $3.000 \mathrm{~m}^{2}$ de área foram entregues em alguns meses. $\mathrm{O}$ arquiteto jogara com a oposição visual entre a estrutura desmaterializada e a vedação homogênea repetitiva: uma caixa elegante e refinada descolada do solo, o envelope dos painéis de fachada em chapa esmaltada completada por acabamento de ângulos arredondados e mata-juntas curvas. No catálogo dos estabelecimentos CIMT/Jean Prouvé, lançado alguns anos antes da construção do Instituto, Jean Prouvé precisava que os painéis eram suficientes por si só e que o "revestimento de uma fachada" consistia em justapor e sobrepor painéis do mesmo tipo. É verdade que o edifício devia

12. O tratamento acústico das piscinas Tournesol (1969-1972, Bernard Schoeller arquiteto) ou a substituição das cascas da sua cobertura são um mercado monopolizado por algumas empresas especializadas que escapam completamente a qualquer lógica arquitetônica e a vigilância dos projetistas originais. 13. Ionel Schein, Paris Construit, Guide de larquitetura contemporaine, edições Vincent, Fréal \& Cie, Paris, 1970. 
suas qualidades a esta arquitetura modesta que se apaga atrás da inteligência do componente. $\mathrm{O}$ debate que aconteceu na hora das tentativas de salvaguardar o Instituto do Meio Ambiente mostrou, claramente, que a inteligência do componente pesava muito pouco na decisão da administração. Acostumada à valorização do ato criador e auxiliada nisto por uma tradição da história da arte que destaca a paternidade da obra como fonte do seu valor, o Instituto do Meio Ambiente, composto de painéis produzidos pela indústria, tinha poucas chances de encontrar defensores.

\section{VALORES SOCIAIS, VALORES ESPACIAIS, INVISIBILIDADE DA ARQUITETURA}

Ao lado do apagamento rápido, dos efeitos do sentimento de culpa dos atores ou da beleza escondida do componente, a especificidade de alguns programas confunde a leitura e a análise. O valor das arquiteturas dos anos 1960 está situado, muitas vezes, fora dos critérios da história tradicional da arte ou daqueles da análise do espaço. A natureza de alguns programas desafia a relação autor-obra herdada da história da arte e é indispensável recorrer à história social para descrever e entender o interesse de algumas realizações.

Assim as operações das 1.000 piscinas ou dos 1.000 clubes de jovens constituem exemplos particularmente significativos da intervenção do Estado Francês no arranjo do território com equipamentos coletivos populares. A operação das 1.000 piscinas, cujo impacto sobre o território e as práticas sociais foi muito importante, produziu um novo objeto, uma piscina com cobertura abre e fecha e industrializada, expressando a crença no futuro e a prática popular dos esportes aquáticos, mas, também, novas relações entre a arquitetura, indústria e a produção em série. A operação dos 1.000 clubes de jovens, nas suas várias versões, reúne encomenda do poder público, industrialização e autoconstrução. Estas especificidades dos programas levaram a uma integração das condições de produção desde a fase de concepção à produção de documentos gráficos adaptados. Marcadas por um valor de uso muito forte, estas arquiteturas modestas geraram, também, representações adaptadas onde a representação das práticas é muitas vezes valorizada. Elas não merecem ser classificadas como monumentos históricos do período?

Ao lado destas arquiteturas modestas, as arquiteturas do período incluem também monumentos que são identificados desde a sua construção, 
comemorados pela imprensa e reconhecidos pelos especialistas. Em 1964, Jean Fayeton foi encarregado de apresentar a arquitetura moderna na França em um número da revista Architecture d'Aujourd'hui ${ }^{14}$. Após desenhar um retrato ingênuo, mas sem complacência da arquitetura francesa no período entre as duas guerras, ele destaca que os "programas de equipamento geral", mais do que a habitação social, podem revelar obras dignas de interesse:

Existe, na França, toda uma arquitetura dedicada aos programas funcionais na qual os franceses colocaram a sua ciência das plantas bem equilibradas ao serviço de uma plástica bem sensata. Se estas obras não são aquelas que abrem novas vias, são bons exemplos da arquitetura contemporânea e dos contratantes, a ideia que a arquitetura moderna atingiu a sua maturidade. É necessário este fundo de certeza para permitir a outros uma pesquisa mais prospectiva ${ }^{15}$ (FAYETON, 1964, p.41).

As ilustrações do artigo de Jean Fayeton incluíam, principalmente, novos programas da arquitetura de depois da Segunda Guerra Mundial: o CNIT no bairro La Défense (1958), a sede da Unesco (1958), a basílica subterrânea de Lourdes (1958), as arquiteturas industriais, terciárias, comerciais ou culturais, mas também os programas tradicionais que tomam dimensões inusitadas pelas quantidades tratadas. Novos tipos são induzidos por programas inéditos, como os conjuntos habitacionais para solteiros (Thionville, 1962, Jean Dubuisson, arquiteto). Novas arquiteturas do quotidiano são destacadas, como as Caldeiras coletivas de ZUP (caldeira central de Massy-Anthony, 1961, G. Leclaire, arquiteto), tipo de pequeno monumento técnico pontuando os conjuntos habitacionais de massa.

\section{DESAPARECIMENTOS?}

A obsolescência destas arquiteturas não provém da desatualização das práticas inicialmente previstas ou da suposta inadequação destas arquiteturas. Na habitação social, a questão da manutenção ou da falta de manutenção, as transformações sucessivas, alterações normativas ou arriscadas embaralharam as cartas. As ameaças de destruição atingem também

14. L'Arquitetura d'Aujourd'hui, Un siècle d'arquitetura, $\mathrm{n}^{\circ}$ 113-114, abril-maio 1964

15. Jean Fayeton, L'Arquitetura d'Aujourd'hui, Un siècle darquitetura, nº 113-114, abril-maio 1964, p.40-53 
exemplos reconhecidos pela história, e que se apresentavam justamente como alternativa à construção banal.

Um conjunto habitacional coletivo, a Cité de l'Etoile, em Bobigny, acumulou as situações paradoxais. Comemorada na sua inauguração, a Cité de l'Étoile é uma operação que segue uma consulta pública vencida pela equipe Candilis Josic Woods: o concurso Milhão, que visava conceber uma habitação econômica de dois quartos por um milhão de francos, em 1955. A solução concebida pela equipe de arquitetos apoia-se numa leitura crítica das soluções "normalizadas". Os arquitetos propuseram configurações de habitações das quais todos os críticos reconheciam o interesse. Bem acabados, os espaços externos incluem parques para as crianças. ${ }^{16}$.

A operação é promovida pelo cliente, a Société d'HLM Emmaüs Habitat, que faz uma ampla propaganda e destaca o seu orgulho de contratante desta realização. Ela é comemorada pela crítica, os filmes, as revistas que destacam as suas qualidades plásticas. Ela é até "patrimonializada" em parte, pois a maquete da Cité de l'Etoile faz parte dos acervos do Museu Nacional de Arte Moderna, Centro Pompidou. Desde os anos 1980, as sucessivas transformações e alterações criaram uma diferença entre o valor histórico e o valor de uso do conjunto, a tal ponto que a beleza inicial da Cité de l'Étoile não é mais perceptível, principalmente pelos seus moradores. Certificada a título de Patrimônio do século XX, a Cité de l'Etoile foi envolvida num processo realizado pela Agência Nacional de Renovação Urbana e escapou por pouco de uma destruição quase total. ${ }^{17}$ Mas a Cité de l'Etoile virou o emblema das situações de conflitos entre a administração patrimonial, o estado, o município, o gestor e os usuários, a tal ponto que a empresa proprietária financiou um filme chamado Ghetto historique, que critica a proteção a título de Monumentos Históricos decidida pelo Ministério da Cultura.

No centro destas situações de conflito existe uma dissociação entre as diversas representações construídas pelos envolvidos sobre esta arquitetura.

\footnotetext{
16. A operação, no seu conjunto, e principalmente este brinquedos para crianças são o objeto de uma reportagem fotográfica bem completa de Véra Cardot e Pierre Joly, no início do ano de 1960. 17. Graças à proximidade com um lugar de memória, a estação ferroviária de Bobigny, que gera um perímetro de proteção, o Arquiteto dos "Bâtiments de France" (Edifícios Franceses) conseguiu emitir um laudo desfavorável à demolição.
} 
Estas representações diferenciadas têm efeitos manifestos no futuro material da salvaguarda destas arquiteturas. Alguns artistas destacaram, recentemente, a importância destas representações oferecendo aos espectadores a possibilidade de deslocar os seus pontos de vista. É o caso de Mathieu Pernot que, ampliando os cartões postais destes conjuntos habitacionais oferece deles uma visão encarnada que ele justapõe com imagens de destruição; ou ainda de Cyprien Gaillard, que os representa sob a forma de gravuras pitorescas. Além disso, os moradores que algumas vezes resistem às destruições mostram um afeto a estas arquiteturas que as instituições, geralmente, não querem reconhecer. É sintomático que os raros casos de transformação que não estão baseadas numa renúncia das formas iniciais destas arquiteturas tenham como consequência mascarar por completo a sua beleza plástica inicial. $\mathrm{Na}$ operação da torre Bois le Prêtre, em Paris, de Frédéric Druot, Anne Lacaton e Jean-Philippe Vassal, uso e a manutenção dos moradores justificaram o modo de transformação - não se pode se esquecer totalmente que a imagem menos publicada é a do estado original do edifício, e que a realização fez desaparecer todos os vestígios da beleza plástica inicial da torre.

\section{CONHECER: CONSIDERAÇÕES}

Lutar contra as evidências ofuscantes significa que é preciso considerar estas arquiteturas como um legado material que devemos, sem dúvida, conhecer melhor, uma herança cultural que devemos entender melhor para relativizar a obsolescência destes edifícios. O inventário destas arquiteturas ainda deve ser feito assim como a restituição de um contexto determinado pelos valores da modernidade, da indústria e da economia. Precisamos revelar valores que não podem ser evidenciados pelos critérios de uma história tradicional da arte. Fora algumas obras monumentais ou singulares observadas na atualidade, já consagradas pela história, as formas principais da arquitetura dos anos do crescimento econômico europeu são as de uma produção de componentes inventivos, inovação tecnológica, novos materiais no contexto dinâmico de renovação das artes plásticas e das ciências humanas. Portanto, é depois de fazer um trabalho visando ao conhecimento destas arquiteturas que poderemos desenvolver estratégias pertinentes de transformação, restauração e modificações deste legado. Estas estratégias poderão, então, afastar os pontos de vista ideo- 
lógicos que nos impedem de olhar com serenidade e, às vezes, entender a beleza plástica destas formas que devem ser agora abordadas sob o ângulo mais positivo da sua contribuição - a nossa cultura contemporânea.

\section{BIBLIOGRAFIA}

AMOUROUX ; CRETTOL ; MONNET. Guide d'arquitetura contemporaine en France. Madrid: AA, Technic-union, 1972.p.379.

CHASTEL, André. Arquitetura et Patrimoine, Inventaire Général. Paris : Imprimerie Nationale, 1994.

FAYETON, Jean. L'Arquitetura d'Aujourd'hui, Un siècle d'arquitetura, $\mathrm{n}^{\circ} 113-114, \mathrm{p} .40-53$, avril-mai 1964.

GRAF Franz ; DELEMONTEY Yvan (dir.). Arquitetura industrialisée et préfabriquée: connaissance et sauvegarde. Lausanne: Presses Polytechniques et universitaires romandes, 2012.

KLEIN Richard. La cité de l'Etoile à Bobigny, Candilis, Josic \& Woods, Créaphis, Paris, 2014.

KLEIN Richard ; MONNIER Gérard (dir.). Les années ZUP, arquiteturas de la croissance 1960-73. Paris : Picard, 2002.

KLEIN Richard; TOULIER Bernard (dir.) L'arquitetura do século XX. Revue de l'Art, Paris, n.186, avril 2014.

MONNIER, Gérard. Larquitetura do século XX, un patrimoine. Paris: Scéren, 2004.

NORA, Pierre (dir.). Science et conscience du patrimoine, éditions du patrimoine. Paris: Fayard, 1997.

TOULIER, Bernard. Arquitetura et patrimoine du XXe siècle en France, éditions du patrimoine. Paris, 1999.

TOULIER, Bernard (dir.). Mille Monuments du XXe siècle en France. Indicateur du Patrimoine, Paris, n.9, Paris, 1997. (Editions du patrimoine)

SCHEIN, Lionel. Paris Construit, Guide de larquitetura contemporaine. Paris: Vincent, Fréal \& Cie, 1970.

\section{Endereços eletrônicos}

Castro Denissof Associés. Disponível em : <http://www.castrodenissof.com>. Acesso em : 12 mai 2011.

\section{Recebido}

23/02/2016

\section{Aprovado}

$16 / 06 / 2016$ 